\title{
Regression in the Symptoms and Discal Hernia in Case of Lumbar Radiculopathy
}

\author{
M. A. Ivanova, V. A. Parfenov, Ekaterina Silina*, A.I. Isaikin \\ Department of Nervous Diseases and Neurosurgery, I.M. Sechenov First Moscow State Medical University (Sechenov \\ University), 8-2 Trubetskaya Street, 119991, Moscow, Russia
}

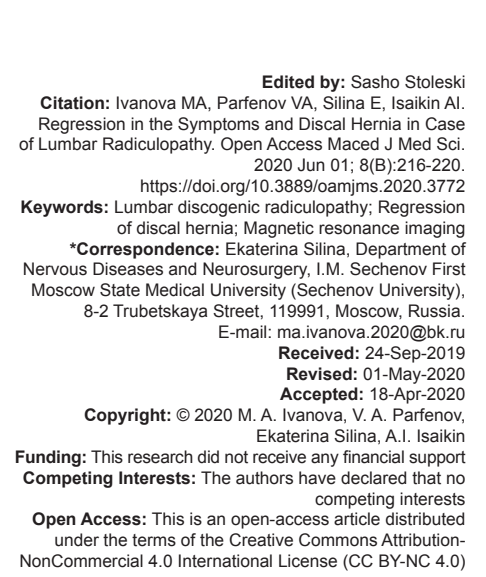

Abstract

BACKGROUND: Discogenic lumbar radiculopathy has a favorable potential for survival; the regression of clinical symptoms may outpace the subsidence of discal hernia.

AIM: The objective of the study is comparing the clinical data and the results of magnetic resonance imaging (MRI) in patients with discogenic lumbar radiculopathy over 1 year of observation.

MATERIALS AND METHODS: Thirty-two patients (13 males at the average age of $39.1 \pm 11.8$ years) with discogenic lumbar radiculopathy confirmed by MRI were examined in the study. The intensity of pain condition was assessed using the numerical rating scale; disability was assessed using the Oswestry disability index. Sixteen patients were subjected to repeated MRI.

RESULTS: Statistically significant $(p<0.01)$ reduction of the average pain intensity and intensity of disability more than 2 times was observed as early as in the first 2 weeks. Gradual reduction of pain and disability was observed during the year. Reduction of discal hernia by more than $50 \%$ was observed on average after $8.7 \pm 4.7$ months.

CONCLUSION: In the case of discogenic radiculopathy, the reduction of pain and related disability far outstrips the regression of the herniation of intervertebral disk.

\section{Introduction}

Back pain is one of the leading reasons for reduced working efficiency and the quality of life of the adult population [1], [2], [3]. According to the diagnostic triad [4], back pain is most frequently caused by the muscular-skeletal (nonspecific) reasons. The second place in the structure of the reasons is taken by discogenic radiculopathy, which is accompanied by the high-intensity pain syndrome, often with the neuropathic component, expressed disability, which determines significant direct and indirect costs [5], [6].

For the treatment of the patients with discogenic radiculopathy, neurosurgical intervention is widely used, which involves the removal of herniated disc with decompression of the radicle. At present, there are not enough data speaking in favor of either surgery technology [7], [8]. Surgical treatment of most patients ensures quick and significant reduction of pain and concomitant disability and is accompanied by the relatively low complication rate [8], [9], [10]. However, in $23-28 \%$ of the patients, pain in the back or a leg remains [8], [11]. Some authors [4], [12], [13], [14] state a favorable prognosis of the natural course of radiculopathy, as well as the possibility of efficient, conservative management of such patients if there are no indications for urgent surgery (e.g., cauda equina syndrome). Epidural administration of corticosteroids (often in combination with local anesthetics) has been considered as the method of conservative treatment with the greatest evidence base [8]. Three ways of introduction are used: Caudal, foraminal, and interlaminar one (no evidence of the preferability for any of them has been obtained yet) [8], [15], [16]. According to the scientifically substantiated guidelines for the diagnosis and treatment of discogenic lumbar radiculopathy of the NASS joint task force [8], conservative treatment may be used to improve the functional outcomes in most patients (evidence level B).

Magnetic resonance imaging (MRI), which in the presence of contraindications may be replaced with computer tomography (level of evidence A), has been rightly considered the key method of confirming the clinical diagnosis of radiculopathy [8]. MRI is widely available; it is not accompanied by exposure to radiation and allows visualizing soft tissues with high accuracy. These advantages have revealed the possibilities for noninvasive study of the herniation of intervertebral disk. The follow-up MRI 
studies revealed cases of discal hernia regression [17], [18], [19], [20]; this article analyses the results of the observation of the patients with discogenic radiculopathy in 1 year.

\section{Materials and Methods}

In 2016-2017, at the Clinic of Nervous Diseases of the Sechenov University, 32 patients (including 13 males at the average age of $39.06 \pm$ 11.82 years) with discogenic lumbar radiculopathy were treated with subsequent follow-up. The clinical diagnosis was confirmed by MRI. MRI was performed on a Siemens Magnetom 3T scanner in standard modes (T1, T2-weighted images, in the sagittal, axial, and frontal planes). During MRI, the presence, size, and localization of hernias, extrusions, and sequestrations were determined. Discal hernia at the level L5-S1 was identified in $65.6 \%$ of the cases, at the level L4-L5 - in $34.4 \%$ of the cases. All patients had previously signed an informed, voluntary consent to participate in the study. The work excluded patients with pelvic disorders, symptoms of the cauda equina syndrome, and neurogenic intermittent claudication caused by lumbar stenosis. The patients underwent epidural introduction of the combination of corticosteroids and local anesthetics. All patients were briefed about the possibility of discal hernia regression, recommendations for a workout, and physical loads. Pain intensity was assessed using the numerical rating scale (NRS), and the degree of physical dysfunction was assessed using the Oswestry disability index. The Oswestry questionnaire was used to evaluate various aspects of life, for each of which there was a degree of restriction on a 5-score system. The Oswestry disability index was calculated in percentage terms as the ratio of the sum of scores received to the maximum possible number of scores.

These indicators were studied at the moment of patients' admission to the clinic, 7-14 days after the start of the treatment, and for a long period after discharge $(3,6$, and 12 months later). To assess the dynamics of the disease morphological pattern, half of the patients were subjected to repeat MRI on the same scanner as when included in the study.

The results were statistically processed using Microsoft Office Excel and IBM SPSS Statistics using nonparametric methods. The dynamics of the associated indicator within one group was determined by the Wilcoxon criterion. Qualitative criteria were evaluated using analysis of contingency tables and criterion $\mathrm{X}^{2}$. Correlation analysis was performed according to the methods of Pearson and Spearman. The differences were considered statistically significant at $p<0.05$.

\section{Results}

On the background of the treatment, a statistically significant positive trend was observed in most patients ( $p<0.01$ compared to initial values) (Figures 1 and 2).

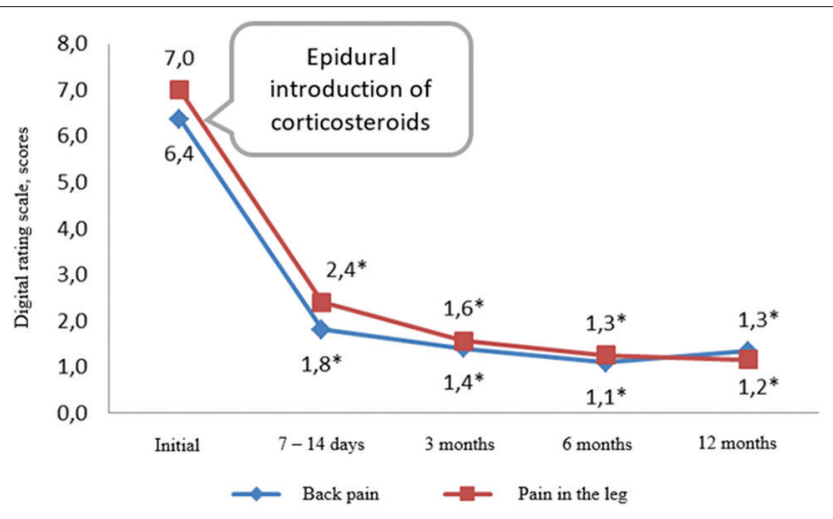

Figure 1: The dynamics of the average intensity of the pain syndrome on the background of treatment. ("the differences are statistically significant compared to the initial values at $p<0.01$ )

The average intensity of back pain decreased from 6.4 to 1.8 scores on the NRS after 7-14 days, with the positive effect preserved during the year (12 months 1.3 scores). As early as in the first 2 weeks of treatment, the average intensity of leg pain decreased from 7.0 to 2.4 scores on the NRS, and after 12 months, the intensity decreased to 1.2 scores. The average Oswestry index decreased from the initial $58.0 \%$ more than 2 times after 7-14 days (to $22.5 \%$ ), and subsequently decreased to $13.3 \%$ within 12 months. The correlation analysis showed no statistically significant relationship between the initial size of the discal hernia and the clinical indicators of patients (intensity of the pain syndrome, the Oswestry disability index), both initial and in the progress of treatment.

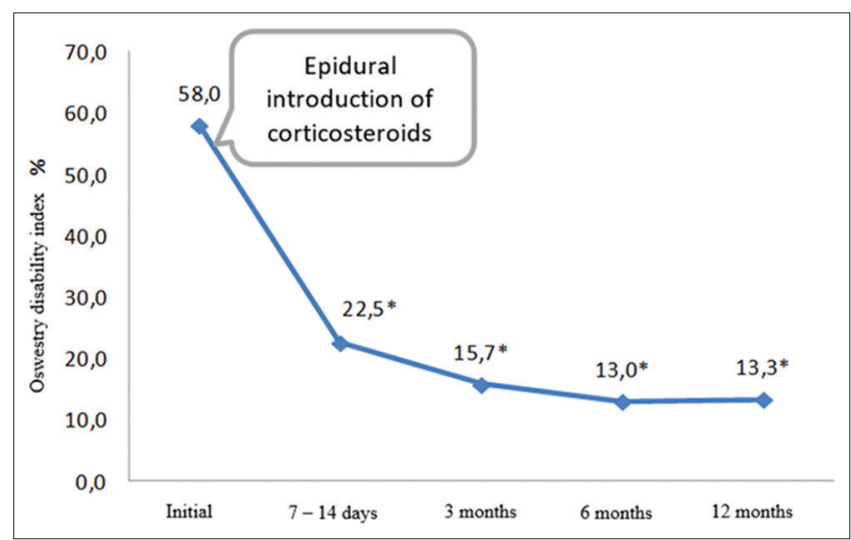

Figure 2: The dynamics of the average Oswestry disability index on the background of treatment. ("the differences are statistically significant compared to the initial values at $p<0.01$ )

In the group of patients who underwent repeated $\mathrm{MRI}$, major extrusions and sequestrations (with the average initial size of $9.7 \pm 0.5 \mathrm{~mm}$ in this subgroup), which were mainly paramedian, were previously diagnosed. In $10(62.5 \%)$ patients, significant 
regression of discal hernia was observed (on average from $9.8 \pm 0.7 \mathrm{~mm}$ to $3.5 \pm 0.5 \mathrm{~mm}$ - by more than $50 \%)$, in two $(12.5 \%)$ patients, reduction of hernia by $<50 \%$ was observed, in three $(18.8 \%$ ) cases, the size of hernia did not change, and in one patient $(6.2 \%)$, discal hernia increased. The average duration of discal hernia significant regression was $8.7 \pm 4.7$ months. Clinical improvement was observed as early as in the $1^{\text {st }}$ days of treatment and significantly outpaced the reduction of discal hernia. Those patients in which the size of hernia reduced insignificantly, or did not change, also experienced a decrease in pain intensity and improved functional status. In a female patient 34 years of age with an extrusion $11 \mathrm{~mm}$ in size, positive dynamics were noted on the background of treatment; however, by the end of 1 year of observation, the patient noted returning and gradually growing pain syndrome with insufficient efficiency of drug treatment. Repeated MRI revealed an increase in the discal hernia up to $14 \mathrm{~mm}$. The patient underwent neurosurgical removal of discal hernia with a quick reduction of the pain syndrome and improvement of the general condition.

\section{Discussion}

The results of the study have shown favorable progress of lumbar discogenic radiculopathy, which is consistent with the data of other authors [4], [12], [13]. Regression of pain and other symptoms occur much sooner than the size of the hernia is reduced, which shows the important role of the inflammation concomitant of hernia and explains the symptomatic efficiency of epidural introduction of steroids [21], [22], [23], [24].

The first description of discal hernia regression in the lumbar spine of a young patient was given by Guinto et al. [25]. The widespread use of the neuroimaging methods has allowed observing both individual cases of discal hernia resorption [18], [26], [28], and series of such cases [17], [19], [20], [29].

A present, the main mechanism of discal hernia regression is considered to be the immunemediated lysis [17], [30], [31], [32], [33], [34], [35]. In the process of its development, the intervertebral disc is formed without contact with the immune system (as an immune-privileged organ). With the degeneration of the disc, the formation of cracks in the fibrous ring and the herniation, the components of nucleus pulposus interact with the immune-competent cells, which perceive it as a foreign body and start the autoimmune reaction. The complex biochemical and immunological cascade is implemented on the activation of antibodyproducing B-lymphocytes and cytotoxic T-lymphocytes. The production of pro-inflammatory cytokines (tumor necrosis factor, interleukins IL-1 $\alpha$, IL-1 $\beta$, IL-6, and IL-17) increases, which contributes to the degradation of the extracellular matrix, and increases the expression of chemokines. This results in the penetration of activated immune cells into the disk, and in the development of endothelial growth factor that promotes neovascularization and ensures an enhancement of phagocytosis and resorption of the fragments of discal hernia. Inflammatory cytokines, such as the tumor necrosis factor-alpha, further stimulate the production of metalloproteinases (particularly, metalloproteinase of type 7 , which causes collagen dissolution). A certain role in reducing discal hernia is also given to its gradual dehydration [30], [31], [32], [33], [34], [35].

In the research, significant regression of discal hernia (reduction by more than $50 \%$ ) was noted in more than half $(62.5 \%)$ of the patients that had undergone repeated $\mathrm{MRI}$, which is consistent with the results of Chiu et al. [30]. In their work, the probability of spontaneous reduction for sequesters reached $96 \%$, for extrusion $-70 \%$, and for protrusions $-41 \%$. The probability of the complete regression for sequesters was $43 \%$, and for extrusions - $15 \%$. The authors noted that large discal hernias caused greater immune responses and, consequently, increased the likelihood of regression. The factors that increased the likelihood of discal hernia resorption included increased T2 signal in MRI (due to the high content of liquid), migration of disc fragments to the epidural space associated with the rupture of the posterior longitudinal ligament, which facilitated the interaction with the immune-competent cells and contrasting of the peripheral parts of hernia, which was evidence of their vascularization and the likelihood of phagocytosis [30], [36].

According to the data of the authors, discal hernia resorption continued for several months. The average duration of significant regression of discal hernia was $8.7 \pm 4.7$ months. In a series of observations of 23 patients by Altun and Yüksel [19], the duration of the reference $\mathrm{MRI}$ ranged from 5 to 22 months. In the study performed by Macki et al. [21], the average duration of discal hernia resorption was $9.3 \pm 13.3$ months.

Significant clinical improvement on the background of complex treatment with the use of epidural injection of corticosteroids was achieved in most patients within the first 2 weeks of treatment, which significantly outpaced the decrease in the size of the discal hernia, and was noted even in the patients without discal hernia regression. With that, no significant correlation was found between the initial size of the hernias and clinical scores. In the study performed by Macki et al. [21], the average duration of discal hernia reduction was $9.27 \pm 13.32$ months, and the regression of clinical symptoms was also noted much earlier, on average after $1.33 \pm 1.34$ months from the onset of the disease. Studying the dynamics of clinical symptoms showed complete removal of back pain, reduction of paresis severity up to $86 \%$, of sensitive violations - up to $68 \%$, and of hyporeflexia - up to $75 \%$. A similar conclusion was also made by el Barzouhi et al. [37] in the study of 
the relationships between the neuroimaging data and the clinical outcome. One year after the disease onset, $84 \%$ of the patients reported good results of treatment. With that, MRI showed remaining discal hernias in 35\% of the patients with a good outcome, and $33 \%$ of the patients with unsatisfactory results of treatment. In the group of patients without discal hernias, the satisfactory results of treatment were observed in $83 \%$ of the patients; however, in the group with a persistent hernia, satisfactory results were noted in $85 \%$ of the cases. The authors concluded that the MRI picture in 1 year after the onset of the disease did not make it possible to differentiate patients with different outcomes of the disease. The work of Autio et al. [36] also stated that discal hernia regression was not always correlated with better disease outcome, and the clinical improvement might also occur without reduction of hernia, which once again confirmed the fact that reduction of the symptoms was determined not only, and not so much by neuroimaging changes.

Thus, the observations show the possibility of intervertebral disks herniations regression in some patients with discogenic radiculopathy. The reduction of pain and related disability far outpace the regression of the herniation of intervertebral disks. It is appropriate to perform large-scale multicenter studies of the prognostic factors of the regression of symptoms and herniations of intervertebral disks.

\section{References}

1. Driscoll T, Jacklyn G, Orchard J, Passmore E, Vos T, Freedman $\mathrm{G}$, et al. The global burden of occupationally related low back pain: Estimates from the Global Burden of Disease 2010 study. Ann Rheum Dis. 2014;73(6):975-81. https://doi. org/10.1136/annrheumdis-2013-204631

PMid:24665117

2. Vos T, Abajobir AA, Abate KH. Global, regional, and national incidence, prevalence, and years lived with disability for 328 diseases and injuries for 195 countries, 1990-2016: A systematic analysis for the global burden of disease study 2016. Glob Heal Metr. Lancet. 2017;390(10100):1211-59. https://doi.org/10.341 O/f.731220250.793569875

\section{PMid:28919117}

3. Stochkendahl MJ, Kjaer P, Hartvigsen J. National Clinical Guidelines for non-surgical treatment of patients with recent onset low back pain or lumbar radiculopathy. Eur Spine J. 2018;27(1):60-75.

PMid:28429142

4. Bardin LD, King P, Maher CG. Diagnostic triage for low back pain: A practical approach for primary care. Med J Aust. 2017;206(6):268-73. https://doi.org/10.5694/mja16.00828 PMid:28359011

5. Ashworth J, Konstantinou K, Dunn KM. Prognostic factors in non-surgically treated sciatica: A systematic review. BMC Musculoskelet Disord. 2011;12(1):208. https://doi. org/10.1186/1471-2474-12-208

PMid:21943339
6. Cook CE, Taylor J, Wright A, Milosavljevic S, Goode A, Whitford M. Risk factors for first time incidence sciatica: A systematic review. Physiother Res Int. 2014;19(2):65-78. https://doi.org/10.1002/pri.1572

PMid:24327326

7. Jacobs WC, Arts MP, Tulder MW. Surgical techniques for sciatica due to herniated disc, a systematic review. Eur Spine J. 2012;21(11):2232-51. https://doi.org/10.1016/j. spinee.2013.01.010

PMid:22814567

8. North American Spine Society. Diagnosis and Treatment of Lumbar Disc Herniation with Radiculopathy. Burr Ridge, Illinois: North American Spine Society; 2012.

9. Weinstein JN, Lurie JD, Tosteson TD, Tosteson AN. Surgical versus non-operative treatment for lumbar disc herniation: Four-year results for the spine patient outcomes research trial (SPORT). Spine. 2009;33(25):2789-800. https://doi. org/10.1097/brs.0b013e31818ed8f4

PMid: 19018250

10. Lurie J, Tosteson T, Tosteson A. Surgical versus nonoperative treatment for lumbar disc herniation: eightyear results for the spine patient outcomes research trial (SPORT). Spine. 2014;39(1):3-16. https://doi.org/10.1097/ brs.0000000000000088

PMid:24153171

11. Shapiro CM. The failed back surgery syndrome: Pitfalls surrounding evaluation and treatment. Phys Med Rehabil Clin N Am. 2014;25(2):319-340.

PMid:24787336

12. Koes BW, van Tulder MW, Peul WC. Diagnosis and treatment of sciatica. BMJ. 2007;334(7607):1313-7. https://doi.org/10.1136/ bmj.39223.428495.be

PMid: 17585160

13. Lequin MB, Verbaan D, Jacobs WC. Surgery versus prolonged conservative treatment for sciatica: 5-year results of a randomised controlled trial. BMJ Open. 2013;3(5):e002534. https://doi.org/10.1136/bmjopen-2012-002534

14. Sutheerayongprasert C, Paiboonsirijit S, Kuansongtham V, Anuraklekha S, Hiranyasthiti N, Neti S. Factors predicting failure of conservative treatment in lumbar-disc herniation. J Med Assoc Thai. 2012;95(5):674-80.

PMid:22994027

15. Chien GC, Knezevic NN, McCormick Z, Chu SK, Trescot AM, Candido KD. Transforaminal versus interlaminar approaches to epidural steroid injections: A systematic review of comparative studies for lumbosacral radicular pain. Pain Phys. 2014;17(4):E509-24. https://doi.org/10.1016/j.pmrj.2013.08.016

16. Manchikanti L, Singh V, Pampati V, Falco FJ, Hirsch JA. Comparison of the efficacy of caudal, interlaminar, and transforaminal epidural injections in managing lumbar disc herniation: Is one method superior to the other? Korean J Pain. 2015;28(1):11-21. https://doi.org/10.3344/kjp.2015.28.1.11 PMid:25589942

17. Kim ES, Oladunjoye AO, Li JA, Kim KD. Spontaneous regression of herniated lumbar discs. J Clin Neurosci. 2014;21(6):909-13. https://doi.org/10.1016/j.jocn.2013.10.008

18. Lu HS, An SÖ, Murkaynak ET. Spontaneous regression of extruded lumbar disc herniation : Report of two illustrative case and review of the literature. Turk Neurosurg. 2008;18(4):392-6. PMid:19107686

19. Altun I, Yüksel KZ. Lumbar herniated disc: Spontaneous regression. Korean J Pain. 2017;30(1):44-50. https://doi. org/10.3344/kjp.2017.30.1.44

PMid:28119770

20. Kim SG, Yang JC, Kim TW, Park KH. Spontaneous regression 
of extruded lumbar disc herniation: three cases report. Korean J Spine. 2013;10(2):78-81. https://doi.org/10.14245/ kjs.2013.10.2.78

PMid:24757463

21. Macki M, Hernandez-Hermann M, Bydon M, Gokaslan $A$, McGovern K, Bydon A. Spontaneous regression of sequestrated lumbar disc herniations: Literature review. Clin Neurol Neurosurg. 2014;120:136-41. https://doi.org/10.1016/j. clineuro.2014.02.013

PMid:24630494

22. Manchikanti L, Benyamin RM, Falco FJ, Kaye AD, Hirsch JA Do epidural injections provide short- and long-term relief for lumbar disc herniation? A systematic review. Clin Orthop Relat Res. 2015;473(6):1940-56. https://doi.org/10.1007/ s11999-014-3490-4

PMid:24515404

23. Bhatti $A B, K i m S$. Role of epidural injections to prevent surgical intervention in patients with chronic sciatica: A systematic review and meta-analysis. Cureus. 2016;8(8):e723. https://doi. org/10.7759/cureus.723

PMid:27625909

24. Risbud MV, Shapiro IM. Role of cytokines in intervertebral disc degeneration: Pain and disc-content. Nat Rev Rheumatol. 2015;10(1):44-56. https://doi.org/10.1038/nrrheum.2013.160 PMid:24166242

25. Guinto FC, Hashim H, Stumer M. CT Demonstration of disk regression after conservative therapy. AJNR Am J Neuroradiol. 1984;5:632-33

PMid:6435432

26. Chang CW, Lai PH, Yip CM, Hsu S.S. Spontaneous regression of lumbar herniated disc. J Chinese Med Assoc. 2009;72(12):6503. https://doi.org/10.1016/s1726-4901(09)70449-6 PMid:20028647

27. Tokmak M, Altiok IB, Guven M, Aras AB. Spontaneous regression of lumbar disc herniation after weight loss: Case report. Turk Neurosurg. 2015;25(4):657-61. PMid:26242347

28. Yang X, Zhang Q, Hao X, Guo X, Wang L. Spontaneous regression of herniated lumbar discs: Report of one illustrative case and review of the literature. Clin Neurol Neurosurg. 2016;143:86-9. https://doi.org/10.1016/j.clineuro.2016.02.020 PMid:26907997
29. Tarukado K, Ikuta K, Fukutoku Y, Tono O, Doi T. Spontaneous regression of posterior epidural migrated lumbar disc fragments: Case series. Spine J. 2015;15(6):e57-62. https://doi. org/10.1016/j.spinee.2013.07.430

PMid:24041917

30. Chiu CC, Chuang TY, Chang KH, Wu CH, Lin PW, Hsu WY. The probability of spontaneous regression of lumbar herniated disc: A systematic review. Clin Rehabil. 2015;29(2):184-95. https:// doi.org/10.1177/0269215514540919

PMid:25009200

31. Kato $T$, Haro $H$, Komori $H$, Shinomiya K. Sequential dynamics of inflammatory cytokine, angiogenesis inducing factor and matrix degrading enzymes during spontaneous resorption of the herniated disc. J Orthop Res. 2004;22(4):895-900. https:// doi.org/10.1016/j.orthres.2003.11.008 PMid: 15183452

32. Lama P, Dolan P, Tarlton JF, Adams MA. Do intervertebral discs degenerate before they herniate, or after? Bone Joint J. 2013;95(8):1127-33. https://doi. org/10.1302/0301-620x.95b8.31660 PMid:23908431

33. Sun Z, Zhang $M$, Zhao $X H$. Immune cascades in human intervertebral disc: The pros and cons. Int J Clin Exp Pathol. 2013;6(6):1009-14. PMid:23696917

34. Haro H. Translational research of herniated discs: Current status of diagnosis and treatment. J Orthop Sci. 2014;19(4):515-20. PMid:24777237

35. Yoshida M, Nakamura T, Sei A, Kikuchi T, Takagi K, Matsukawa A. Intervertebral disc cells produce tumor necrosis factor alpha, interleukin-1beta, and monocyte chemoattractant protein-1 immediately after herniation: An experimental study using a new hernia model. Spine. 2005;30(1):55-61. https://doi. org/10.1097/01.brs.0000149194.17891.bf

36. Autio RA, Karppinen J, Niinima J, Vanharanta H, Tervonen O. Determinants of spontaneous resorption of intervertebral disc herniations. Spine. 2006;31(11):1247-52. https://doi. org/10.1097/01.brs.0000217681.83524.4a

37. el Barzouhi A., Vleggeert-Lankamp, C.L.A.M., Nijeholt, G.J. Magnetic resonance imaging in follow-up assessment of sciatica. N Engl J Med. 2013;368(11):999-1007. https://doi. org/10.1056/nejmoa1209250

PMid:23484826 